\title{
CFD Simulations of the IHF Arc-Jet Flow: Compression- Pad/Separation Bolt Wedge Tests
}

\author{
Tahir Gökçen ${ }^{*}$ and Kristina A. Skokova ${ }^{\dagger}$ \\ AMA Inc., NASA Ames Research Center, Moffett Field, CA 94035
}

\begin{abstract}
This paper reports computational analyses in support of two wedge tests in a high enthalpy arc-jet facility at NASA Ames Research Center. These tests were conducted using two different wedge models, each placed in a free jet downstream of a corresponding different conical nozzle in the Ames 60-MW Interaction Heating Facility. Panel test articles included a metallic separation bolt imbedded in the compression-pad and heatshield materials, resulting in a circular protuberance over a flat plate. As part of the test calibration runs, surface pressure and heat flux measurements on water-cooled calibration plates integrated with the wedge models were also obtained. Surface heating distributions on the test articles as well as arc-jet test environment parameters for each test configuration are obtained through computational fluid dynamics simulations, consistent with the facility and calibration measurements. The present analysis comprises simulations of the nonequilibrium flowfield in the facility nozzle, test box, and flowfield over test articles, and comparisons with the measured calibration data.
\end{abstract}

\section{Introduction}

Arc-jet facilities provide the primary means to study the performance of various types of thermal protection systems (TPS) used on the outer surfaces of spacecraft in an aerothermodynamic heating environment. In a high enthalpy arc-jet facility, a test gas, usually air or a mixture of nitrogen, oxygen and argon, is passed through an electric arc discharge where the energy is added to the flow. The test gas is then expanded through a convergingdiverging nozzle into an evacuated test chamber to produce high-enthalpy supersonic or hypersonic flow. NASA Ames Research Center (ARC) has four arc-jet facilities within its Arc-Jet Complex. ${ }^{1}$

Since Avcoat, the thermal protection system used on the Orion and Apollo spacecraft, does not have the mechanical strength to support the mechanical loads between the crew module and service module during launch, densified compression-pads are used to support these loads. As a result of one compression-pad design, circular recessed cavities or protuberances are embedded in the heatshield. ${ }^{2-3}$ These cavities or protuberances disturb the flow during reentry, producing augmented heating locally and downstream of the cavities. A related compressionpad system design results in a protuberance on the compression-pad material and heatshield. The present arc-jet tests are conducted in the NASA Ames 60-MW Interaction Heating Facility (IHF) to evaluate a particular compressionpad design and to investigate effects of the melting metallic separation bolt used in the design on performance of the compression-pad and heatshield materials. Two separate tests, making use of two different blunted wedge holders, were conducted in the IHF conical nozzles. In order to characterize the aerothermodynamic heating environment over the test articles, a calibration plate with an array of heat flux calorimeter and pressure gages was used.

In support of these arc-jet wedge tests, computational fluid dynamics (CFD) simulations are used: (1) to characterize the arc-jet test environment and its parameters consistent with the facility and calibration measurements; and (2) to provide surface quantities and input for material thermal response and thermal stress analyses. The primary objective of the proposed paper is to report these CFD simulations. The present analysis comprises computational Navier-Stokes simulations of the nonequilibrium flowfield in the facility nozzle and test box as well as the flowfield over the models, and comparisons with the experimental measurements.

\footnotetext{
" Senior Research Scientist, MS 230-2, Associate Fellow AIAA

${ }^{\dagger}$ Senior Research Scientist, MS 234-1
} 


\section{Arc-Jet Facility and Tests}

The Interaction Heating Facility (IHF) at NASA ARC consists of a constricted arc heater, a 60-MW DC power supply, interchangeable conical and semi-elliptical nozzles, a test chamber, and supplementary systems including steam ejector vacuum system, cooling-water system and data acquisition system. The IHF is designed to operate with a set of conical nozzles or a semi-elliptical nozzle at total pressures of 1-9 atm and total bulk enthalpies of 2-28 $\mathrm{MJ} / \mathrm{kg}$ (air). ${ }^{4}$ The 60 -MW constricted arc heater produces high-temperature test gas for both nozzles. The conical nozzle configurations of the IHF are suitable for tests of stagnation coupon and blunted wedge models in hypersonic flow, while the semi-elliptical nozzle configuration is designed mainly for testing flat panels in hypersonic boundary-layer heating environments. Figure 1 shows a schematic diagram of the IHF with its interchangeable nozzles and a photograph of a wedge test.

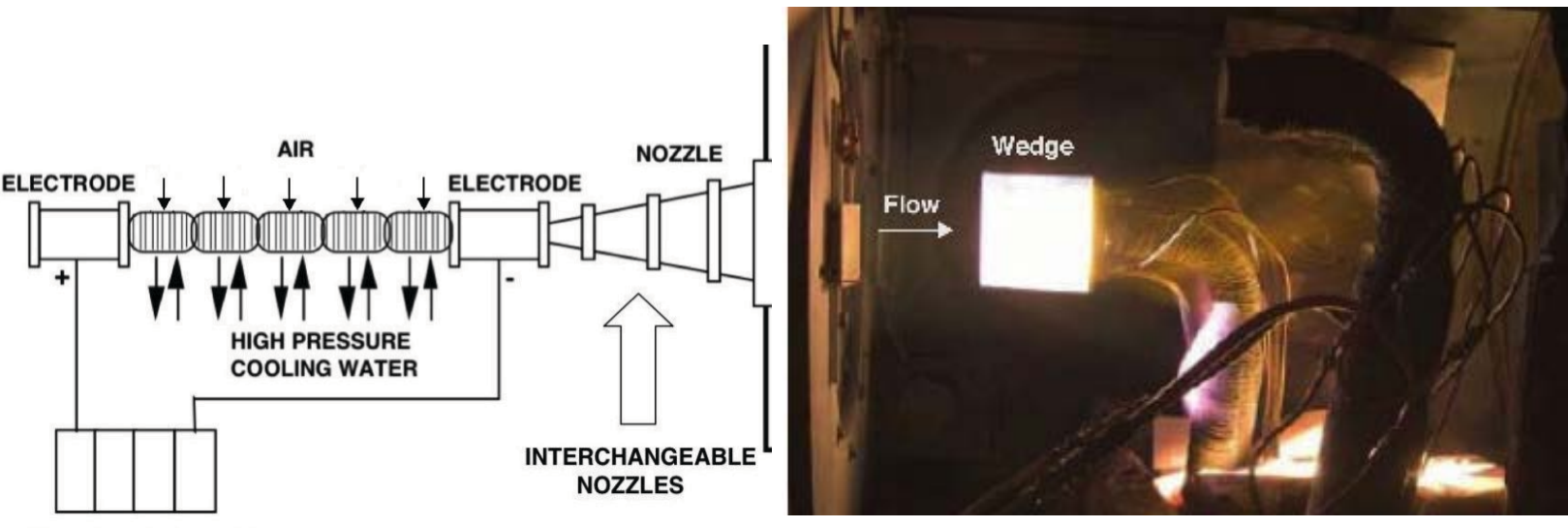

DC POWER SUPPLY

(a) IHF arc-heater/nozzles sketch

(b) Wedge model in a conical nozzle test

Figure 1. IHF sketch and a photograph of a conical nozzle/wedge test.

For the proposed paper, analyses of the two wedge tests conducted using two different IHF nozzles are considered. The first one is the IHF 13-inch conical nozzle using a 9.2-inch wide wedge holder, and th second one is the IHF 6-inch conical nozzle using a smaller 7-inch wide wedge holder. Both IHF 6-inch and 13-inch nozzles have the same throat diameter of $6.033 \mathrm{~cm}$ (2.375 in) and the same $10^{\circ}$ half-angle for the diverging section, while their exit diameters are $15.24 \mathrm{~cm}(6 \mathrm{in})$ and $33.02 \mathrm{~cm}(13 \mathrm{in})$, respectively. Note that the IHF 6-inch nozzle also includes a $40^{\circ}$ extension piece $\left(4.6 \mathrm{~cm}\right.$ long) attached to the nozzle exit. The larger wedge model has a $30^{\circ}$ half-angle, a nose radius of $1.27 \mathrm{~cm}$, and $23.37 \mathrm{~cm}$ width, while the smaller wedge has a $20^{\circ}$ half-angle, a nose radius of $0.9525 \mathrm{~cm}$, and a width of $17.78 \mathrm{~cm}$. Both wedge models are made of copper and water-cooled, and they can accommodate either a calibration plate or a TPS sample plate for testing. Both calibration plates are instrumented with 6 Gardon gage calorimeters and 3 pressure transducers. Figure 2 shows photographs of the two wedge models, each mounted with a calibration plate and a test article. Test articles used include one or two TPS panels and an imbedded bolt (or a protuberance) with different diameters and heights. 


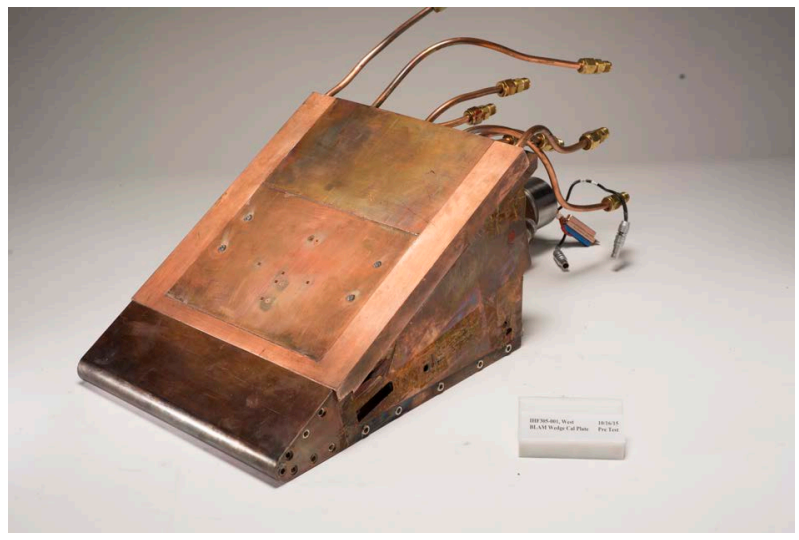

(a) 9.2-in wedge model, calibration plate

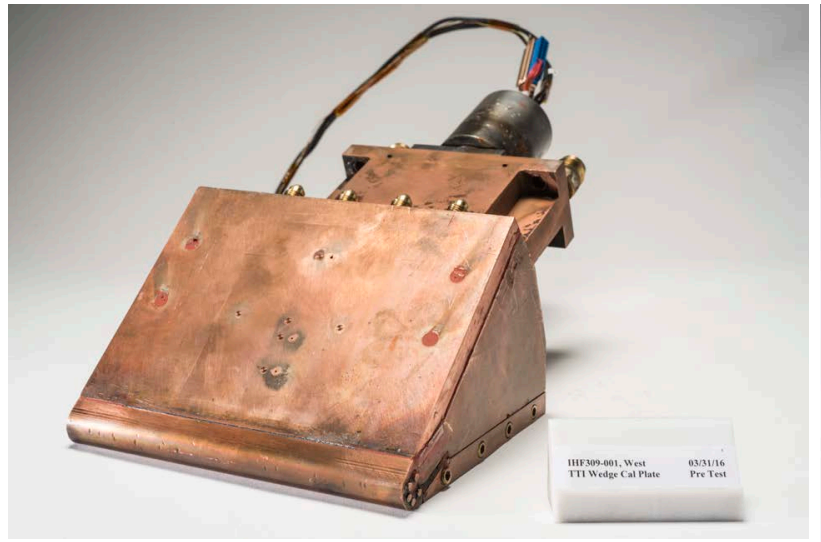

(c) 7-in wedge model, calibration plate

Figure 2. Photographs of two wedge models.

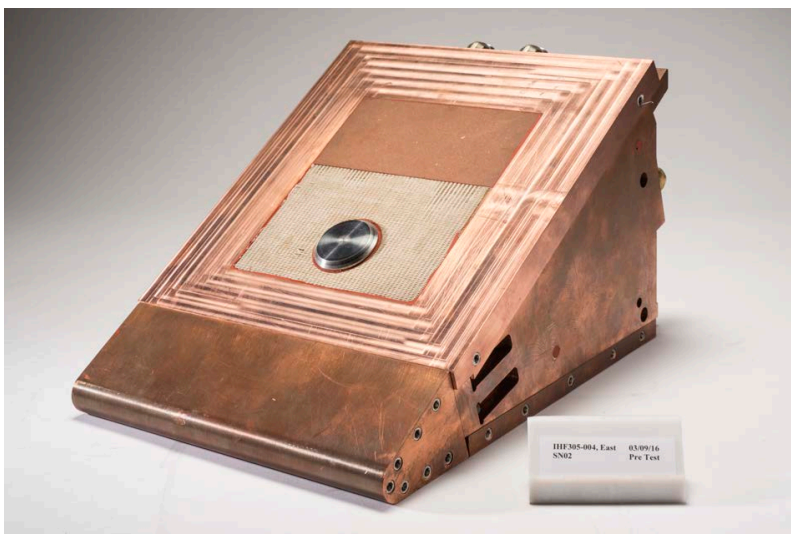

(b) 9.2-in wedge model, test article

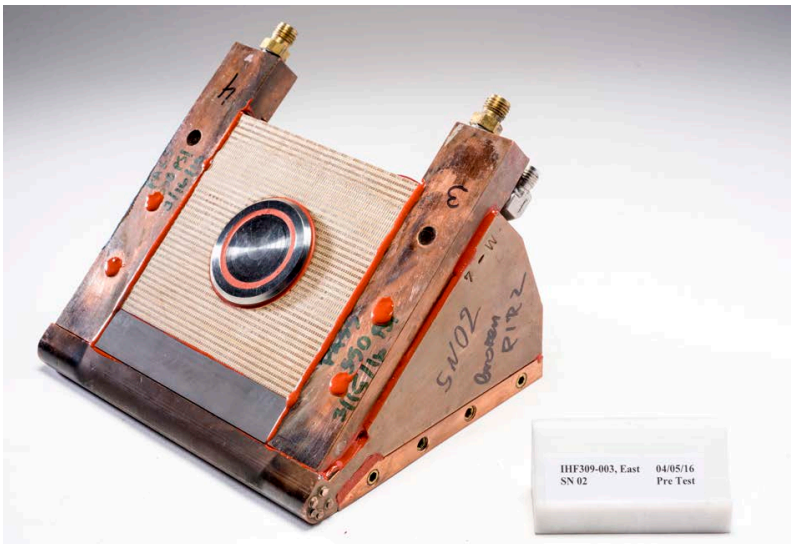

(d) 7-in wedge model, test article

\section{Computational Approach}

Computational analyses of arc-jet tests are performed through simulation of nonequilibrium expanding flow in the arc-jet nozzle and supersonic jet, and simulation of the flow in the test box and around the test articles. For all CFD calculations, the Data Parallel Line Relaxation (DPLR) code, ${ }^{5,6}$ a NASA Ames in-house flow solver, is used. DPLR has been employed extensively at Ames for hypersonic flight, planetary entry and arc-jet simulations. DPLR provides various options for thermophysical models and formulation. For CFD calculations presented in this paper, two-dimensional axisymmetric or three-dimensional Navier-Stokes equations, supplemented with the equations accounting for nonequilibrium kinetic processes, are used in the formulation. The thermochemical model employed for the arc-jet flow includes six species $\left(\mathrm{N}_{2} \mathrm{O}_{2}, \mathrm{NO}, \mathrm{N}, \mathrm{O}, \mathrm{Ar}\right)$, and the thermal state of the gas is described by two temperatures (translational-rotational and vibrational-electronic) within the framework of Park's two-temperature model. $^{7}$

The flowfield in an arc-jet facility, from the arc heater to the test section, is a very complex, three-dimensional flow with various nonequilibrium processes occurring. In order to simulate the flowfield, several simplifying assumptions are made, and corresponding numerical boundary conditions are prescribed for CFD simulations. The present computational approach follows our earlier work, ${ }^{8-10}$ and it is also briefly described here. 
Simulations of the arc-jet facility flow are started from the nozzle inlet. The total enthalpy and its radial profile at the inlet is prescribed based on the facility and calibration data, and the flow properties at the inlet are assumed to be in thermochemical equilibrium. Measured facility data, namely, the total pressure, mass flow rate, and test box pressure, are used as boundary conditions. The calibration data obtained include stagnation calorimeter heat flux and pressure in the freestream. All metallic surfaces, water-cooled nozzle walls, and calorimeter model surfaces (copper slug or Gardon gages), are assumed to be fully catalytic to recombination reactions of atomic oxygen and nitrogen at a constant temperature of $500 \mathrm{~K}$. The test box is included in CFD simulations, primarily to account for the free jet expansion formed by the under-expanded flow exiting the nozzle to the test box and its potential effects on model flowfields. The jet expansion within the test box is primarily determined by the test box static pressure, which is one of the facility measurements and is prescribed as a boundary condition. Further details of the computational approach will be included in the proposed paper.

\section{Computational Simulations}

\section{A. Stagnation calorimeter model simulations}

The primary objective of the stagnation model calculations is to estimate the centerline total enthalpy of the arcjet flow consistent with the facility and calorimeter measurements. As an illustration of a typical axisymmetric simulation, Fig. 3 shows a computed IHF 13-inch nozzle flowfield including the test box and a stagnation calorimeter model. Stagnation calorimeters are used to calibrate the test conditions, and to infer the centerline total enthalpy of the arc-jet flow.

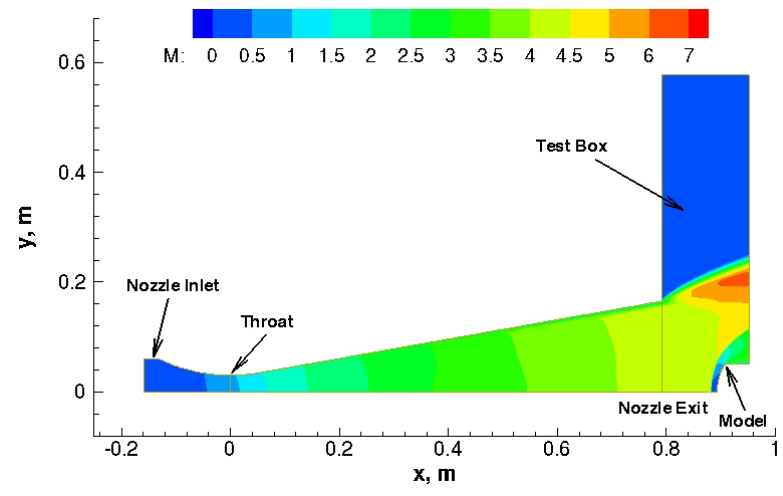

(a) Mach number

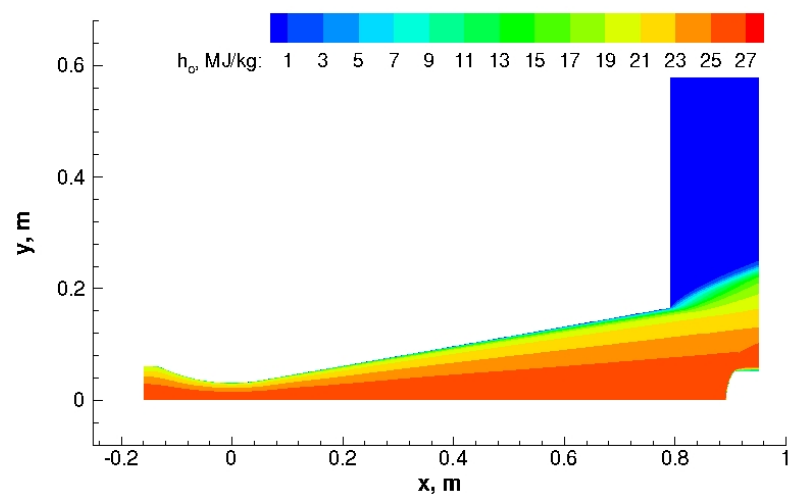

(b) total enthalpy

Figure 3. Computed IHF 13-inch nozzle flowfield including the test box and a 10.16-cm diameter iso-q calorimeter model: $\dot{m}=849 \mathrm{~g} / \mathrm{s}, h_{o b}=22.8 \mathrm{MJ} / \mathrm{kg}, h_{o c l}=26.7 \mathrm{MJ} / \mathrm{kg}$, parabolic enthalpy profile, $6.4 \%$ Ar, $p_{\text {box }}=2$ torr.

At the nozzle inlet, uniform pressure and a non-uniform parabolic enthalpy profile are specified such that the centerline calibration data are reproduced with the computations. It is important to reproduce both measured surface pressure and heat flux with CFD simulations in order to estimate the centerline total enthalpy. Note that the estimation of centerline total enthalpy from CFD simulations this way is analogous to the ASTM standard E637$05,{ }^{11}$ except that the calorimeter surface heat flux and pressure are predicted by CFD simulations, replacing the heat transfer theory used in the standard.

As mentioned earlier, two different wedge model holders were used in two different nozzles. The larger wedge model (the $30^{\circ}$ wedge) was used in the 13 -inch nozzle, while the smaller wedge model (the $20^{\circ}$ wedge) was used in the 6-inch nozzle. Representative CFD simulation results from both wedge configurations are now presented. 


\section{B. IHF 13-inch nozzle flow $/ 30^{\circ}$ wedge model simulations}

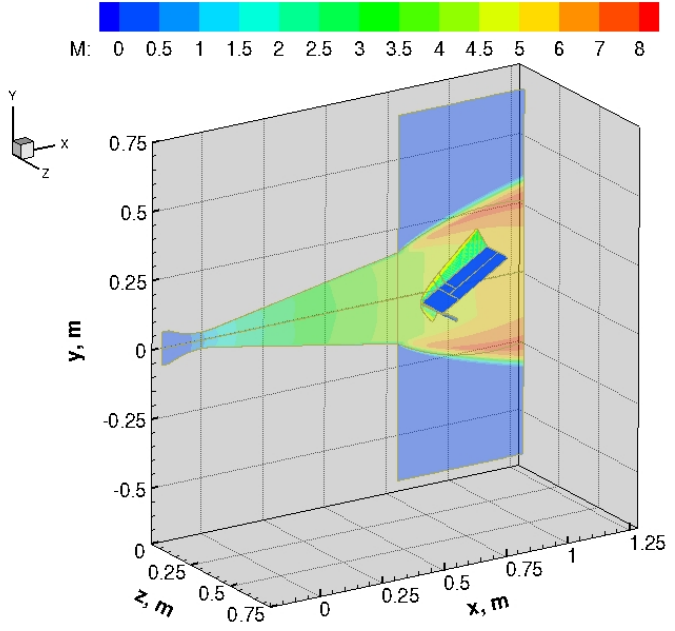

(a) Mach number

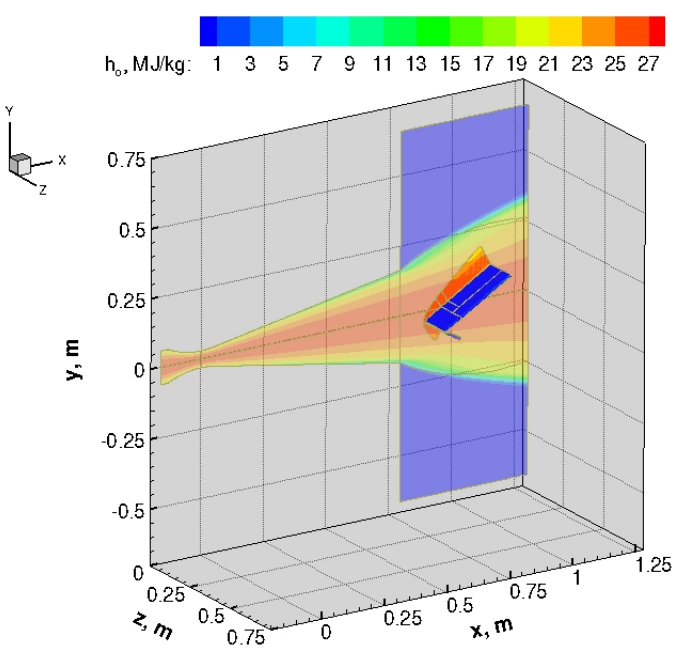

(b) total enthalpy

Figure 4. Computed flowfield contours of the IHF 13-inch nozzle flow and test box with the $30^{\circ}$ wedge model: $\dot{m}=849 \mathrm{~g} / \mathrm{s}, h_{o b}=22.8 \mathrm{MJ} / \mathrm{kg}, h_{o c l}=26.7 \mathrm{MJ} / \mathrm{kg}$, parabolic enthalpy profile, $6.4 \% \mathrm{Ar}, p_{b o x}=2 \mathrm{torr}$.

Figure 4 shows the computed Mach number and total enthalpy contours of the IHF 13-inch nozzle flow downstream of the nozzle inlet. The contours are shown on the x-y symmetry planes of the nozzle flowfield and on other planes of interest for the flowfield of the test box and over the wedge model. The expansion waves emanating from the nozzle lip at the exit to the test box ordinarily affect the shape and strength of the shock formed over the wedge model, thus affecting the pressure distribution on the model. For this case, the wedge model was therefore tested at an off-centerline location (the leading edge of the wedge model is at $10.16 \mathrm{~cm}$ downstream of the nozzle exit and $3.81 \mathrm{~cm}$ below centerline) in order to reduce the effects of the expansion wave on the model surface pressure.

Figure 5 shows contours of the computed surface quantities (pressure and heat flux) of the wedge model and the calibration plate. Note that the surface pressure drops significantly along the wedge centerline. The pressure drop observed along the plate centerline is primarily due to the following two factors: three-dimensional conical flow expansion over the side of the model (cross flow effects), and interaction of the expansion waves from the nozzle exit with the bow shock wave of the wedge model. As expected, the effect of the expansion wave becomes increasingly dominant when the model size and the nozzle exit diameter are comparable. Also shown in Fig. 5 are comparisons of computed calibration-plate surface quantities with the measured calibration data. The contour plots show computed surface pressure and heat flux on one half of the calibration plate, and the symbols in the contour plots are the measurements, color coded with the same contour levels. A complete uncertainty analysis of the calibration plate measurements is not available. However, based on empirical evidence (historical Ames arc-jet data with similar measurements), the heat flux measurements are estimated to be accurate to within $\pm 15 \%$ and the pressure measurements to within $\pm 5 \%$. Note that computed and measured surface pressure values are in good agreement. The agreement in the rate of pressure drop along the plate centerline indicates that wave interaction and three dimensional effects are adequately captured by the computations. Also note that the agreement in the heat flux values is reasonable but not as good as in pressure values, especially at the first calorimeter location near the plate leading edge.

Figure 6 shows the geometry of the $30^{\circ}$ wedge model with the test plate and computed surface surface temperature contours. The water-cooled copper sections of the model are assumed to be at a constant temperature of $500 \mathrm{~K}$ while the test plate temperatures are computed using a radiative equilibrium boundary condition. 

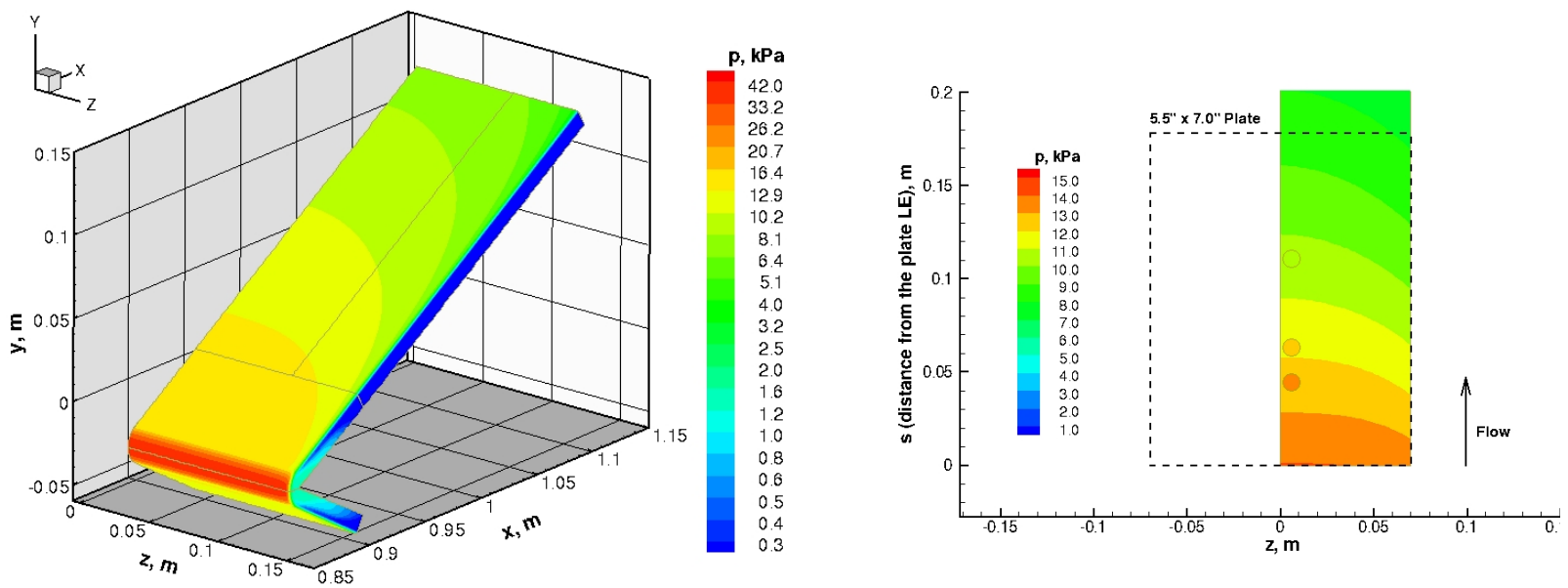

(a) pressure
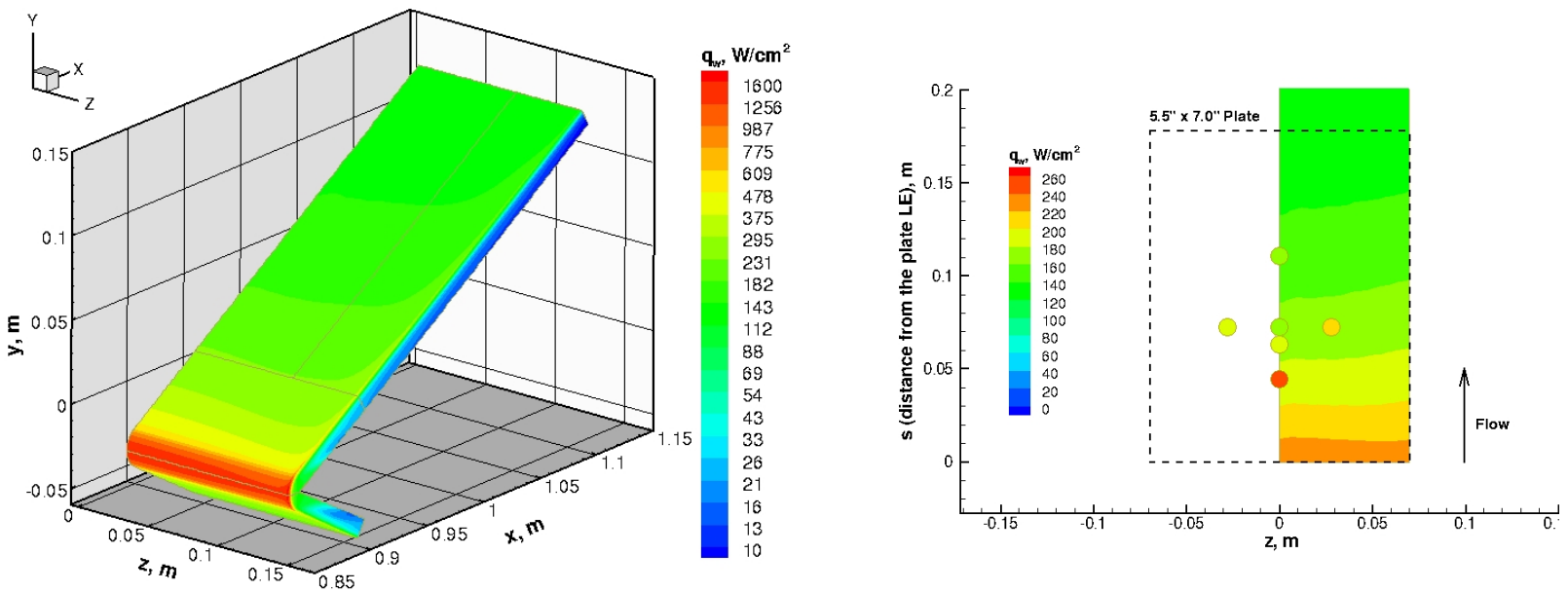

(b) heat flux

Figure 5. Computed surface quantities of the $30^{\circ}$ wedge model with the water-cooled calibration plate and

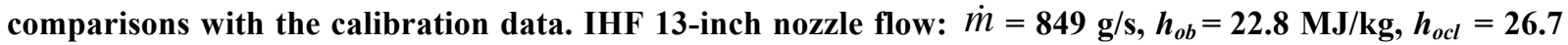
$\mathrm{MJ} / \mathrm{kg}$. Symbols color-coded with the contour colors are the test data from IHF 305 Run 3-1.

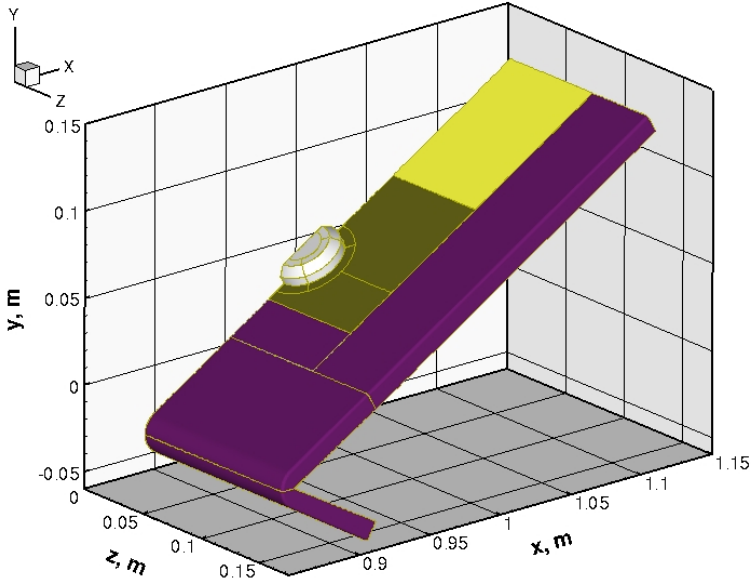

(a) 9.2-in wedge model geometry

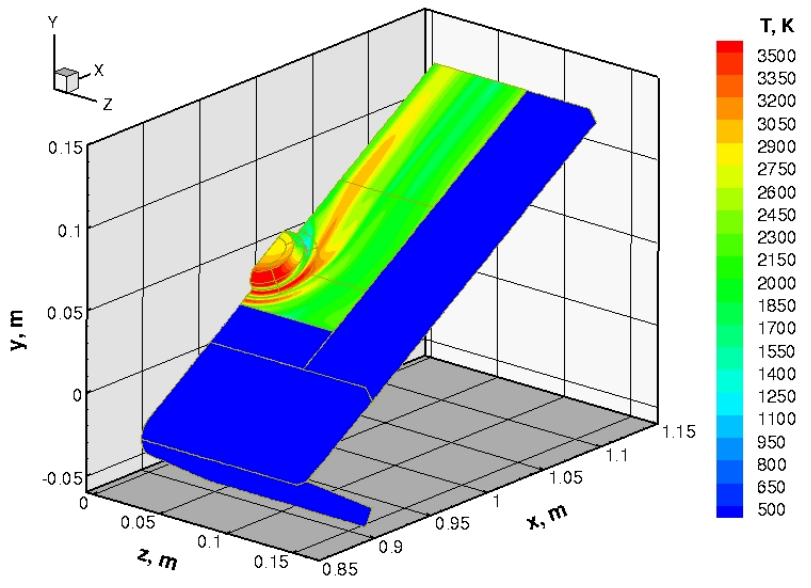

(b) surface temperature

Figure 6. Geometry of the $30^{\circ}$ wedge model with the test plate and computed surface surface temperature contours. IHF 13-inch nozzle flow: $\dot{m}=849 \mathrm{~g} / \mathrm{s}, h_{o b}=22.8 \mathrm{MJ} / \mathrm{kg}, h_{o c l}=26.7 \mathrm{MJ} / \mathrm{kg}$. 

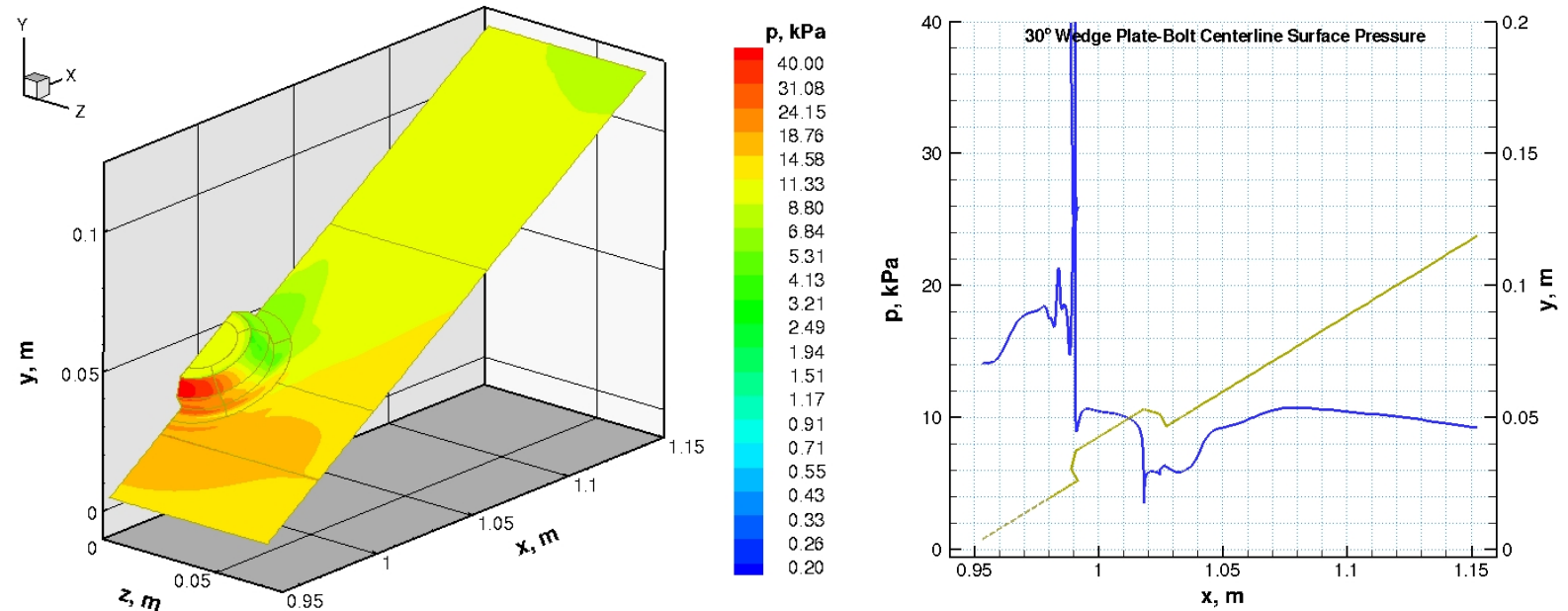

(a) pressure
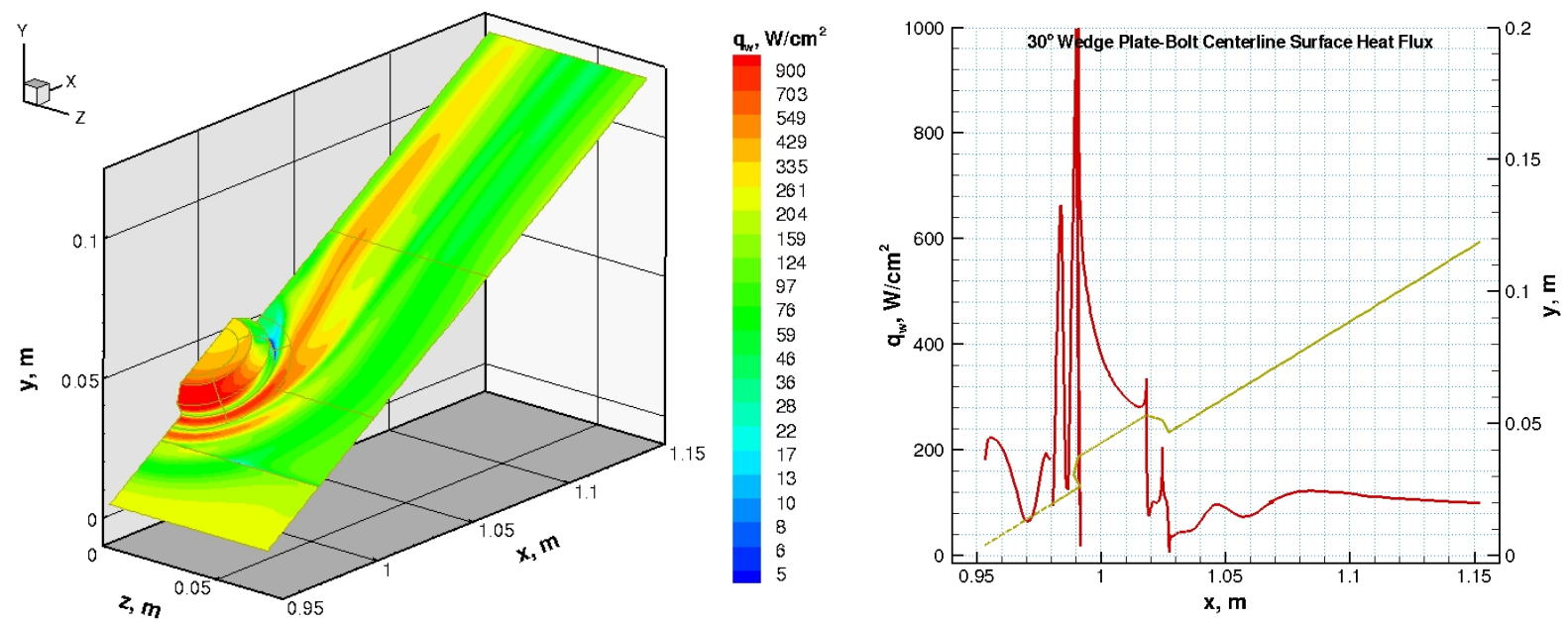

(b) heat flux
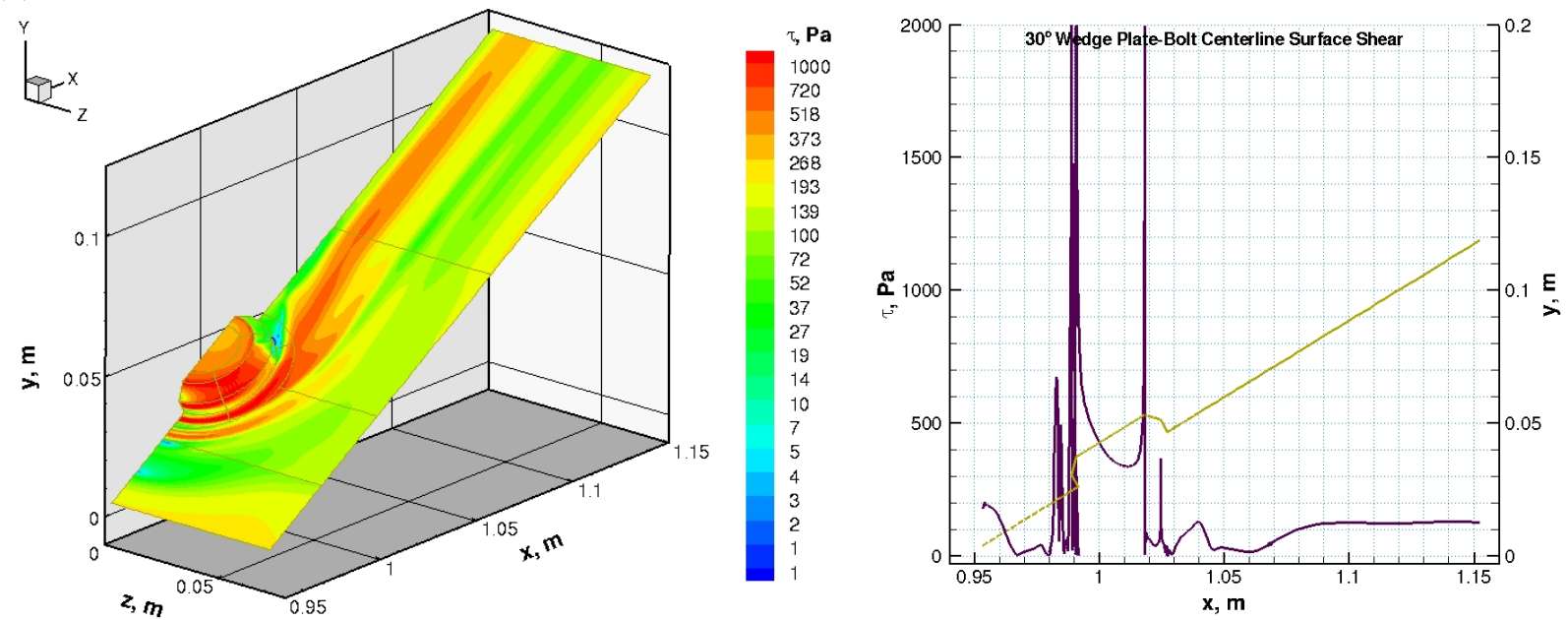

(c) shear

Figure 7. Computed surface quantities of the test plate using the $30^{\circ}$ wedge model. IHF 13-inch nozzle flow: $\dot{m}=849 \mathrm{~g} / \mathrm{s}, h_{o b}=22.8 \mathrm{MJ} / \mathrm{kg}, h_{o c l}=26.7 \mathrm{MJ} / \mathrm{kg}$. 
Figure 7 shows contours of the computed surface pressure, heat flux and shear stress on one half of the test plate with the bolt and the corresponding profiles along the plate centerline. In order to make interpretation of the centerline profiles easier, the geometry of the test plate is also shown. On the line plots, the dashed line represents the water-cooled copper plate surface upstream of the test plate. Note that the flow around the bolt is complex and three-dimensional. Due to the bolt protrusion, flowfield upstream of the bolt is separated, and two shock waves are formed. CFD simulations predict that a separation bubble is formed at the leading of the bolt. The first shock wave originates at the upstream of this bubble. As a result of shock-wave boundary layer interaction, the flow separation region extends upstream, and another shock wave is formed at the reattachment point. Note that for this case the separated flow region extends upstream of the test plate leading edge to the copper wedge plate. Two augmented heating regions upstream of the bolt (and around the bolt) are predicted by CFD simulations. (Details of the flowfield features near the bolt will be presented in the proposed paper.) The heat flux contours in Fig. $7 \mathrm{~b}$ clearly show these two augmented heating regions around the bolt. The computed surface shear stress contours are also shown in Fig. 7c. These contours provide additional information about stagnant and separated regions in the flowfield, as these regions exhibit relatively low shear levels (e.g., at both upstream and downstream of the bolt).

At this point, it is useful to show qualitative heating patterns observed during the tests and make qualitative comparisons with CFD predictions. During the IHF 305 tests, the test articles were viewed with a HD video camera and an IR camera from the top. HD video footage and IR temperature maps of the wedge test plates are provided from the test facility as qualitative data. Figure 8 presents HD and IR images of the wedge test article. These images, taken right before the separation bolt started to melt, provide qualitative heating distributions on the test article. In comparison with the CFD heat flux predictions presented in Fig. 7b, they show qualitatively similar distributions.

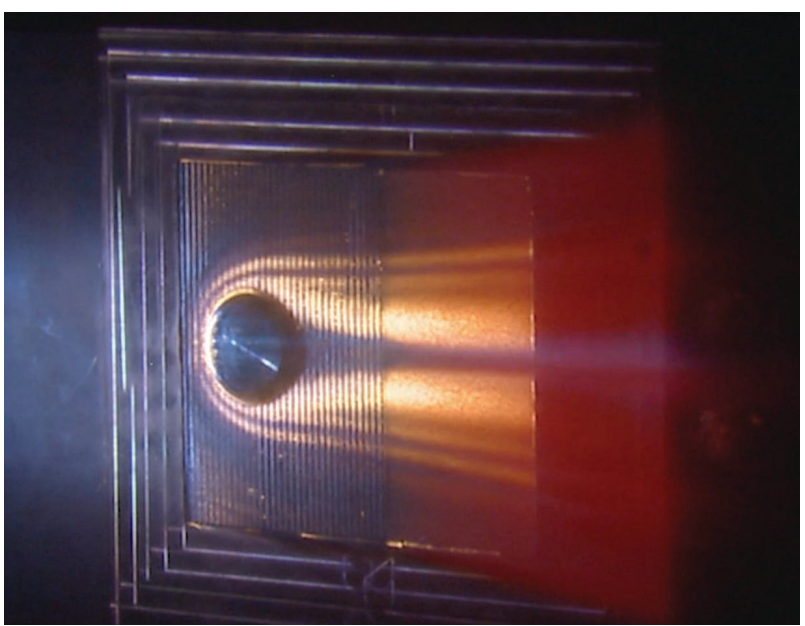

(a) HD camera image

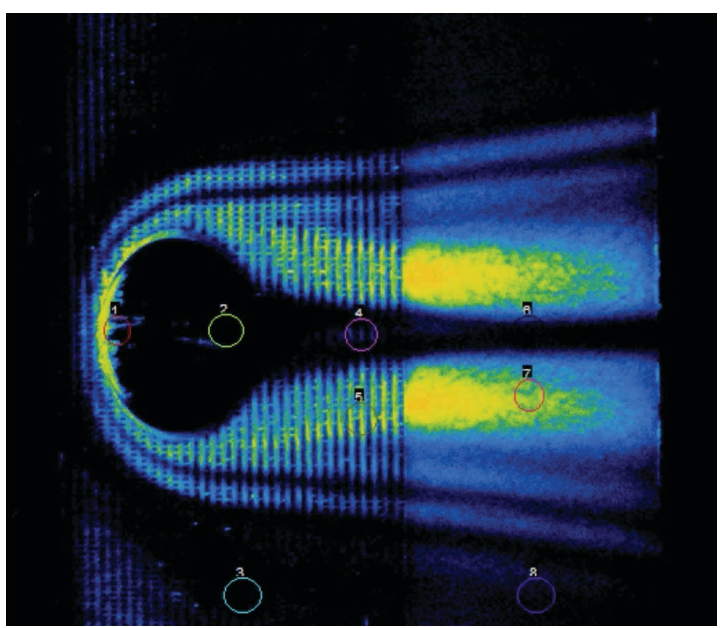

(b) IR camera image

Figure 8. Qualitative heating patterns observed from the HD and IR cameras, IHF 305 Run 5. The $30^{\circ}$ wedge model in the IHF 13-inch nozzle flow. 


\section{IHF 6-inch nozzle flow $/ 20^{\circ}$ wedge model simulations}

Figure 9 shows the computed Mach number and total enthalpy contours of the IHF 6-inch nozzle and test box flow. The contours are shown on the x-y symmetry planes of the nozzle flowfield and on other planes of interest for the flowfield of the test box and over the wedge model. The expansion waves emanating from the nozzle lip at the exit to the test box ordinarily affect the shape and strength of the shock formed over the wedge model, thus affecting the pressure distribution on the model.

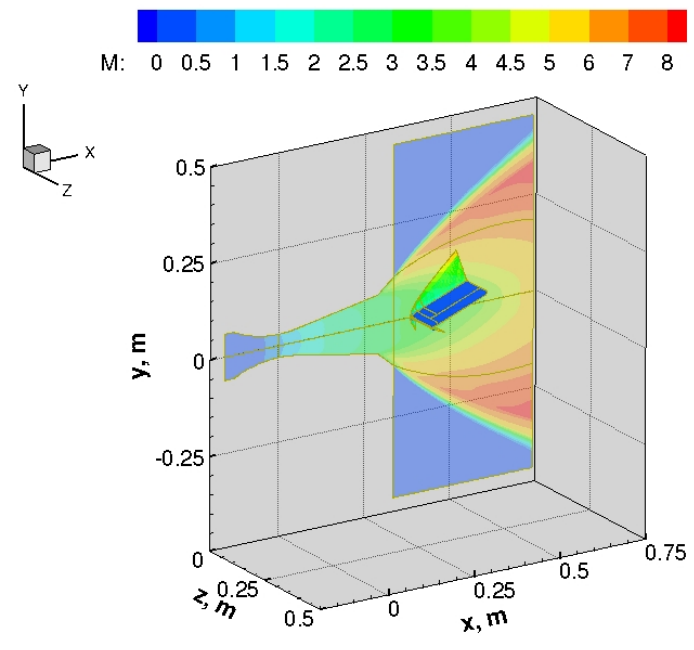

(a) Mach number

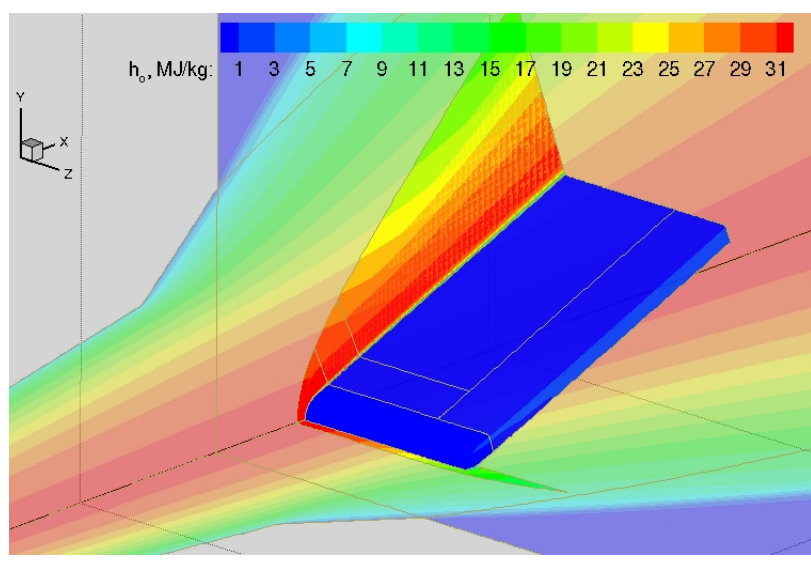

(b) total enthalpy

Figure 9. Computed flowfield contours of the IHF 6-inch nozzle flow and test box with the $20^{\circ}$ wedge model: $\dot{m}=849 \mathrm{~g} / \mathrm{s}, h_{o b}=20.9 \mathrm{MJ} / \mathrm{kg}, h_{o c l}=31.7 \mathrm{MJ} / \mathrm{kg}$, parabolic enthalpy profile, $6.4 \%$ Ar, $p_{b o x}=2 \mathrm{torr}$.

Figure 10 shows contours of the computed surface quantities (pressure and heat flux) of the $20^{\circ}$ wedge model and the calibration plate. Both computed and measured surface pressure and heat flux values are in reasonable agreement.

Figure 11 shows the geometry of the $20^{\circ}$ wedge model with the test plate and computed surface surface temperature contours. Note that for this wedge model, there is a graphite conditioning plate upstream of the test plate.

Finally, contours of the computed surface pressure, heat flux and shear stress of the test plate using the $20^{\circ}$ wedge model and the corresponding profiles along the plate centerline are presented in Fig. 12.

These CFD predictions along with the calibration plate measurements characterize the arc-jet test environments, and predicted surface quantities are then fed into material/thermal response analysis of the compression-pad bolt model. Analyses of the test data from these two wedge tests are currently in progress. In the proposed paper, further details of the computed flowfields for the two wedge tests and additional comparisons with the test data will be presented. 

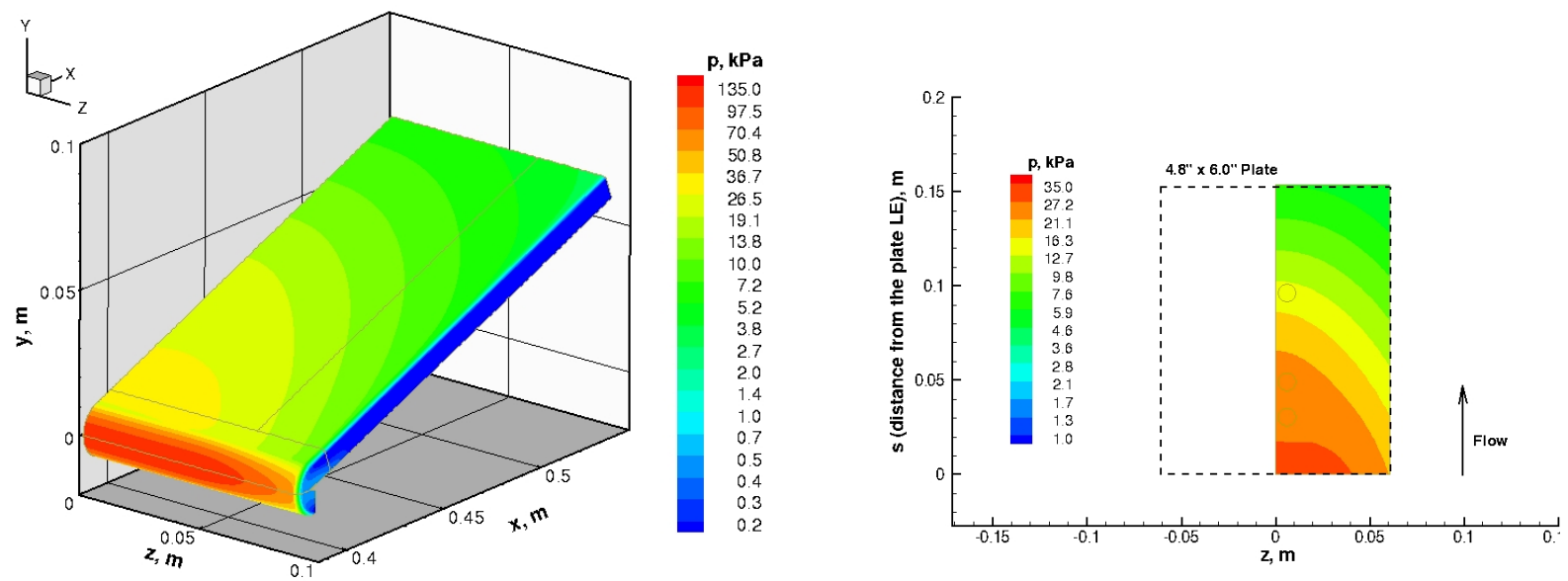

(a) pressure
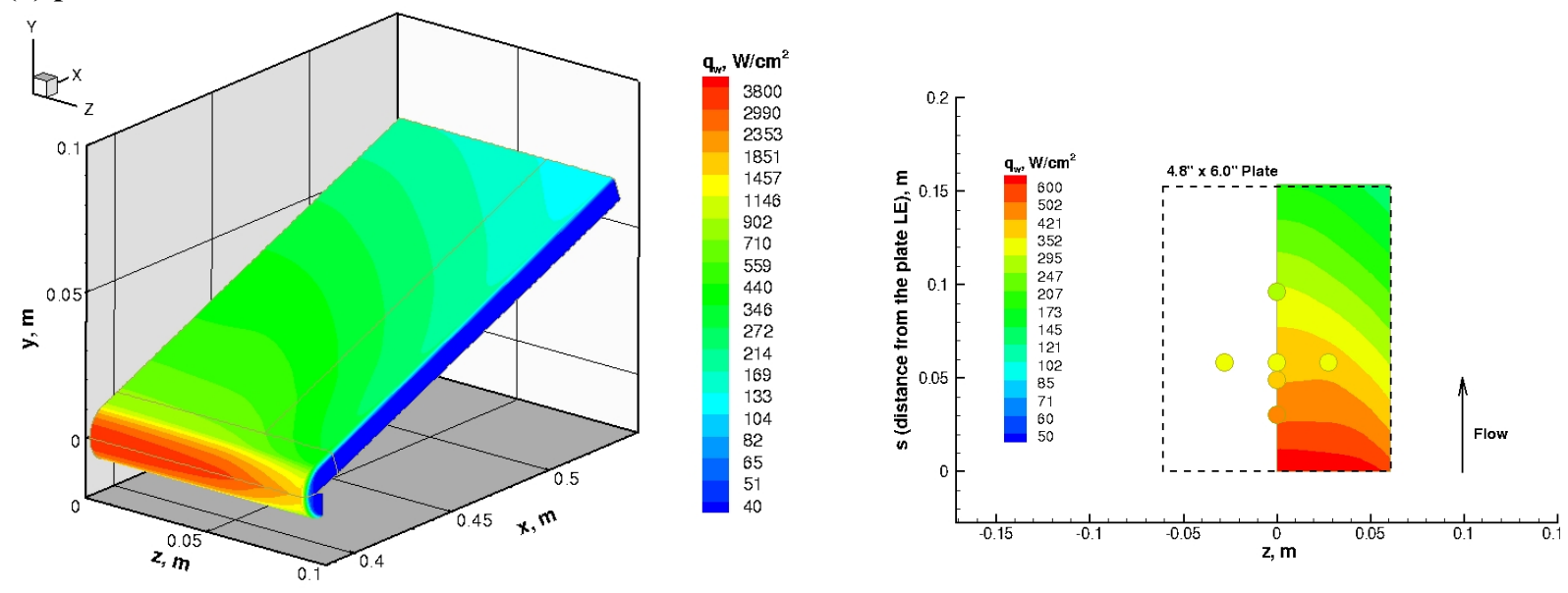

(b) heat flux

Figure 10. Computed surface quantities of the $20^{\circ}$ wedge model with the water-cooled calibration plate and comparisons with the calibration data. IHF 6-inch nozzle flow: $\dot{m}=849 \mathrm{~g} / \mathrm{s}, \boldsymbol{h}_{o b}=20.9 \mathrm{MJ} / \mathrm{kg}, \boldsymbol{h}_{\text {ocl }}=$ $31.7 \mathrm{MJ} / \mathrm{kg}$. Symbols color-coded with the contour colors are the test data from IHF 309 Run 2-1.

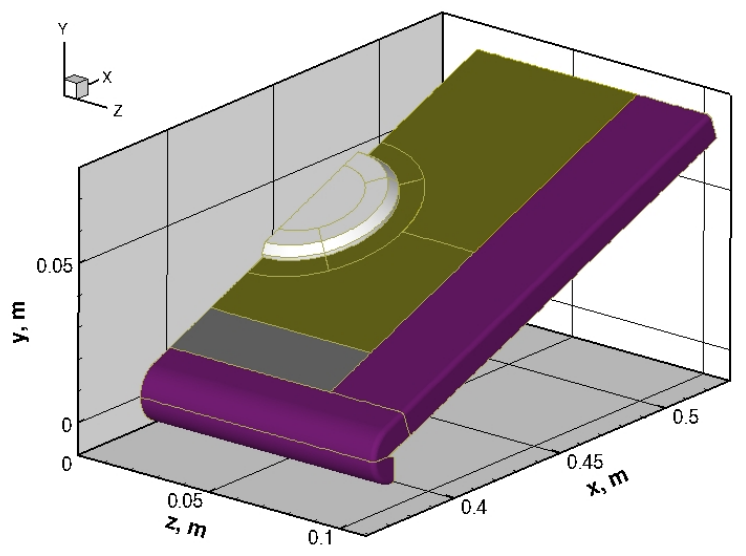

(a) 7 -in wedge model geometry $\left(20^{\circ}\right.$ wedge $)$

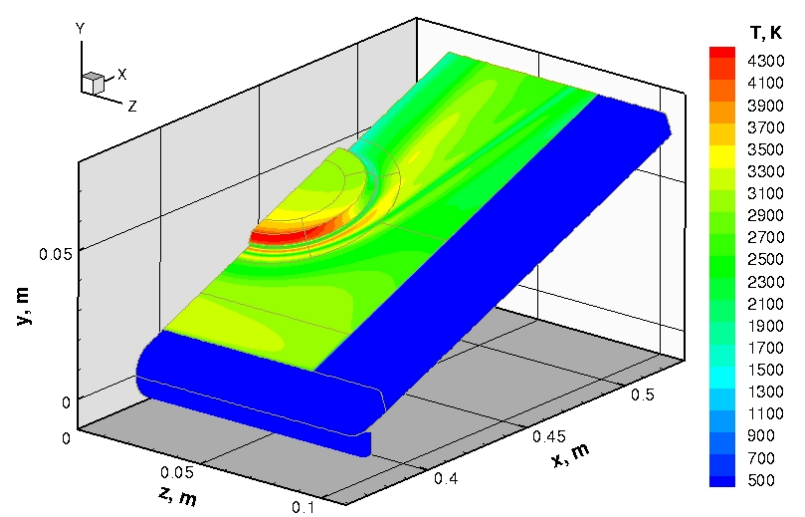

(b) surface temperature

Figure 11. Geometry of the $20^{\circ}$ wedge model with the test plate and computed surface surface temperature contours. IHF 6-inch nozzle flow: $\dot{m}=849 \mathrm{~g} / \mathrm{s}, h_{o b}=20.9 \mathrm{MJ} / \mathrm{kg}, h_{o c l}=31.7 \mathrm{MJ} / \mathrm{kg}$. 

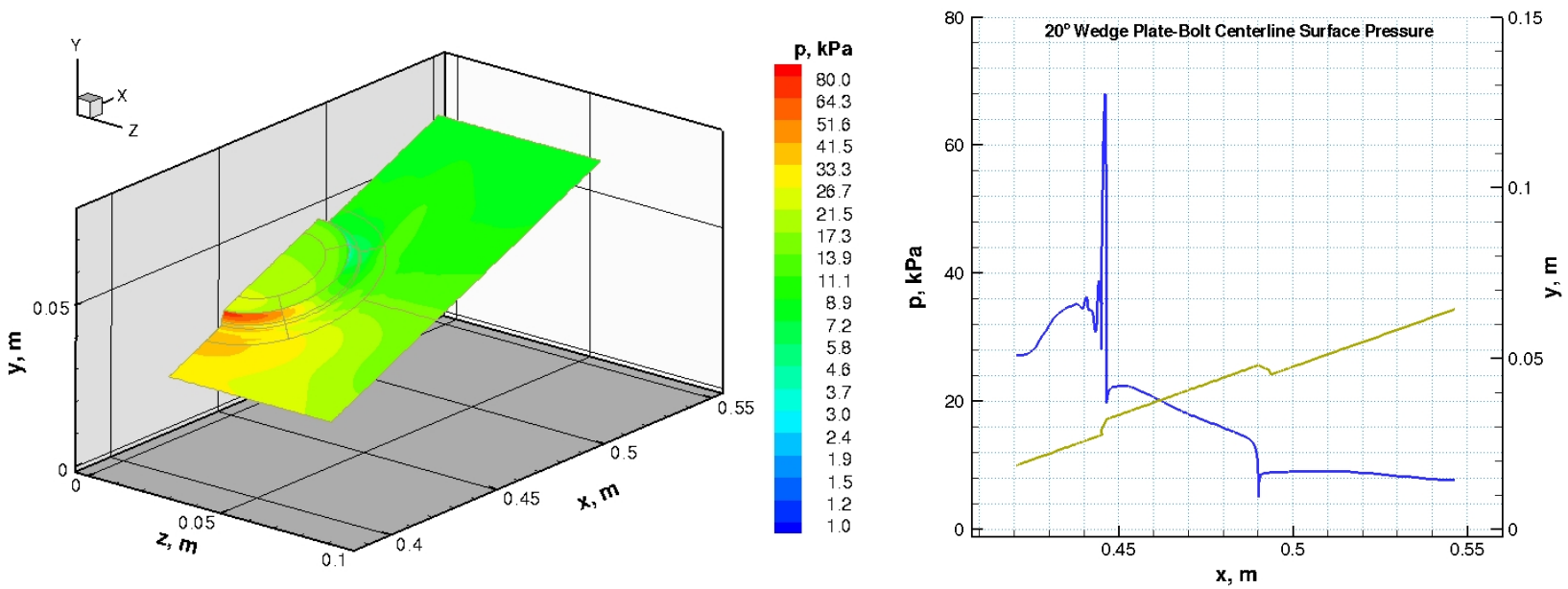

(a) pressure
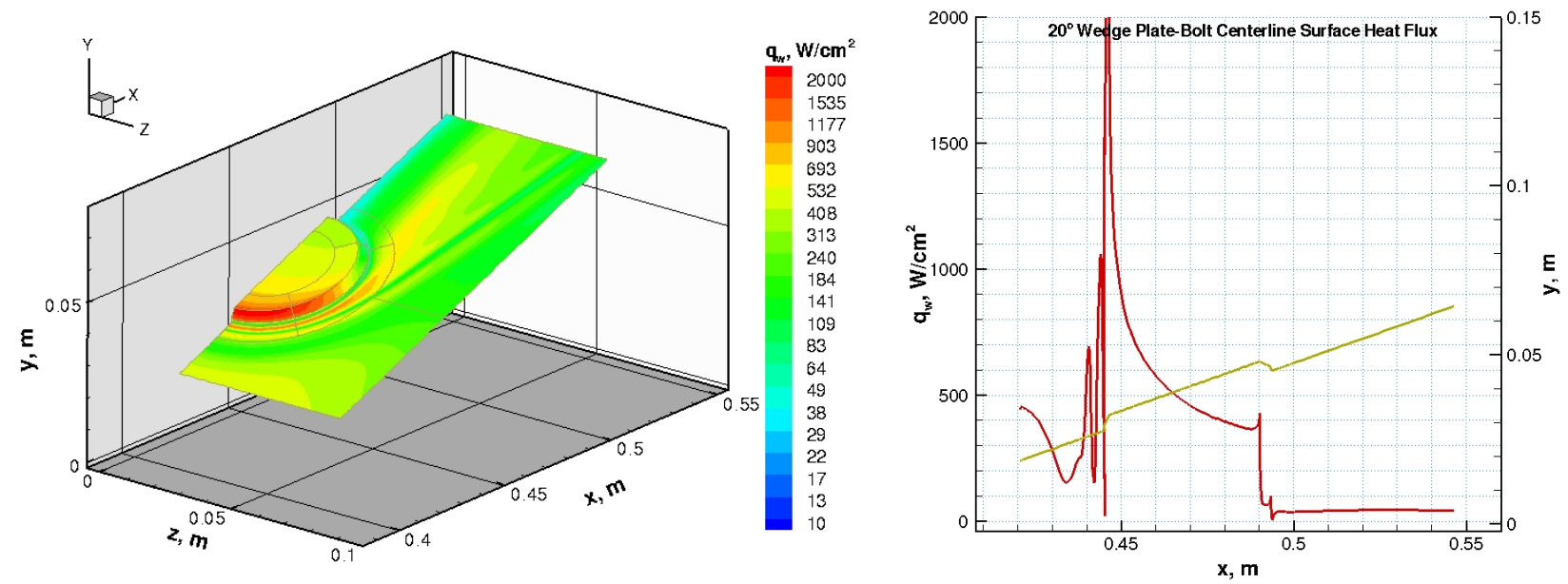

(b) heat flux
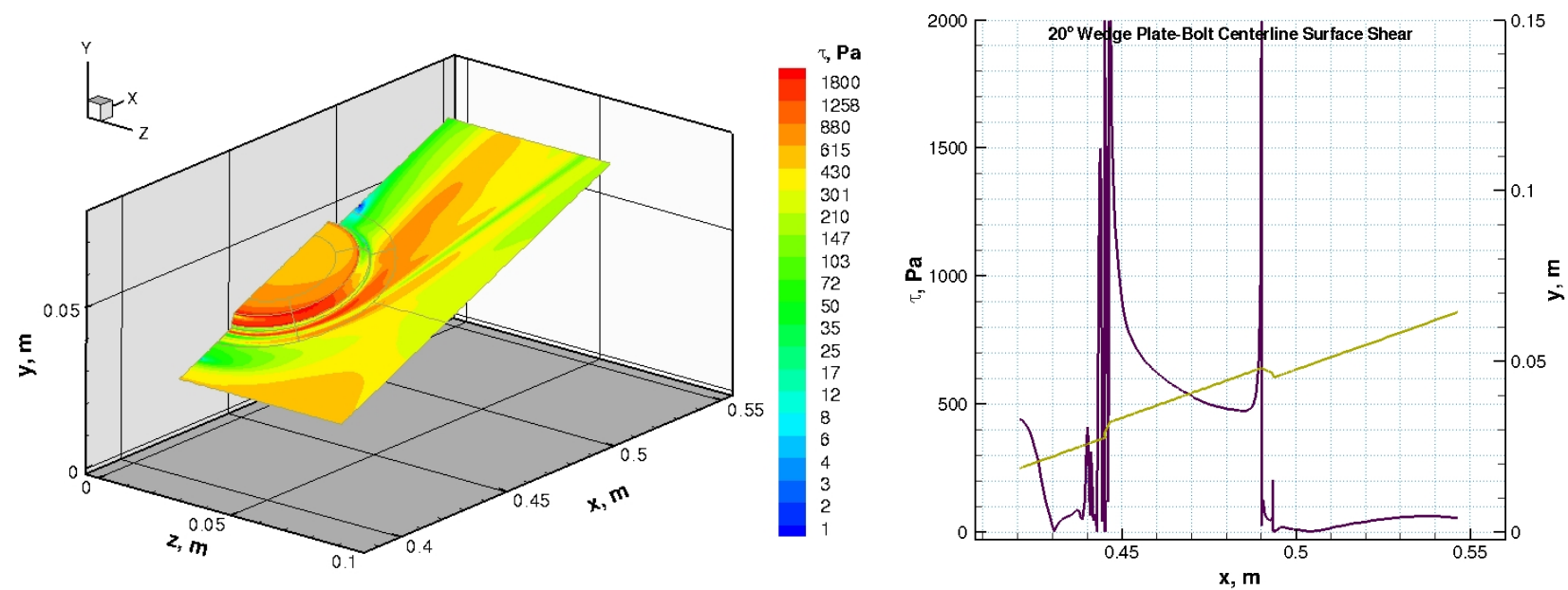

(c) shear

Figure 12. Computed surface quantities of the test plate using the $\mathbf{2 0}^{\circ}$ wedge model. IHF 6-inch nozzle flow: $\dot{m}=849 \mathrm{~g} / \mathrm{s}, h_{o b}=20.9 \mathrm{MJ} / \mathrm{kg}, h_{o c l}=31.7 \mathrm{MJ} / \mathrm{kg}$. 


\section{Acknowledgments}

This work was funded by the NASA Orion TPS Insight/Oversight project. The arc-jet operational capability at NASA ARC is also supported by NASA-SCAP. The authors would like to thank Eric I. Esposito of Lockheed Martin Space Systems for the compression-pad/separation bolt test article designs, and all of the facilities staff involved in the IHF tests, in particular, test engineers Frank C. L. Hui and Imelda Terrazas-Salinas. The support from the NASA Ames Entry Systems and Technology Division, through contract NNA15BB15C to AMA, Inc., is gratefully acknowledged.

\section{References}

${ }^{1}$ Terrazas-Salinas, I., and the staff of Thermophysics Facilities Branch, "Test Planning Guide for NASA Ames Research Center Arc-Jet Complex and Range Complex," A029-9701-XM3 Rev. C, Entry Systems and Technology Division, NASA Ames Research Center, April 2009.

${ }^{2}$ Thompson, R. A., Lessard, V., Jentink, T., and Zoby, E. V. “Analysis of Compression Pad Cavities for the Orion Heatshield,” AIAA Paper 2009-1575, Jan. 2009.

${ }^{3}$ Hollis, B. R., "Compression Pad Cavity Heating Augmentation on Orion Heat Shield," Journal of Thermophysics and Heat Transfer, Vol. 25, No. 3, 2011, pp. 329-340; also AIAA Paper 2009-3843, June 2009.

${ }^{4}$ Fretter, E., "Interaction Heating Facility (IHF) Fact Sheet," http://www.nasa.gov/centers/ames/thermophysicsfacilities-home, Thermophysics Facilities Branch, Entry Systems and Technology Division, NASA Ames Research Center, Sept. 2016.

${ }^{5}$ Wright, M. J., Candler, G. V., and Bose, D., "Data-Parallel Line Relaxation Method for the Navier-Stokes Equations," AIAA Journal, Vol. 36, No. 9, 1998, pp. 1603-1609.

${ }^{6}$ Wright, M. J., “Data-Parallel Line Relaxation Code, DPLR Version 4.02,” Private Communication, June 2010.

${ }^{7}$ Park, C., Nonequilibrium Hypersonic Aerothermodynamics, John Wiley \& Sons, Inc., New York, 1990, Chap. 4.

${ }^{8}$ Gökçen, T., Skokova, K., Balboni, J. A., Terrazas-Salinas, I., and Bose, D., "Computational Analysis of Arc-Jet Wedge Calibration Tests in IHF 6-Inch Conical Nozzle,” AIAA Paper 2009-1348, Jan. 2009.

${ }^{9}$ Gökçen, T., Chen, Y. K., Skokova, K. A., and Milos, F. S., "Computational Analysis of Arc-Jet Stagnation Tests Including Ablation and Shape Change," Journal of Thermophysics and Heat Transfer, Vol. 24, No. 4, 2010, pp. 694-707; also AIAA Paper 2009-3596, June 2009.

${ }^{10}$ Gökçen, T., Balboni, J. A., and Alunni, A. I. "Computational Simulations of the 10-MW TP3 Arc-Jet Facility," AIAA Paper 2015-3103, June 2015.

${ }^{11}$ ASTM E637-05, "Standard Test Method for Calculation of Stagnation Enthalpy from Heat Transfer Theory and Experimental Measurements of Stagnation-Point Heat Transfer and Pressure," American Society for Testing and Materials, November 2005 (originally published in 1978). 